\title{
PET/CT-guided biopsies of metabolically active bone lesions: applications and clinical impact
}

\author{
Bernd Klaeser • Jakub Wiskirchen • Jan Wartenberg • \\ Thilo Weitzel • Ralph A. Schmid • Michel D. Mueller • \\ Thomas Krause
}

Received: 23 March 2010 / Accepted: 3 June 2010/Published online: 3 August 2010

(C) Springer-Verlag 2010

\begin{abstract}
Purpose In a minority of cases a definite diagnosis and stage grouping in cancer patients is not possible based on the imaging information of PET/CT. We report our experience with percutaneous PET/CT-guided bone biopsies to histologically verify the aetiology of hypermetabolic bone lesions.

Methods We retrospectively reviewed the data of 20 consecutive patients who underwent multimodal imageguided bone biopsies using a dedicated PET/CT system in a step-by-step technique. Technical and clinical success rates of PET/CT-guided biopsies were evaluated. Questionnaires were sent to the referring physicians to assess the impact of biopsies on patient management and to check the clinical need for PET/CT-guided biopsies.

Results Clinical indications for biopsy were to histologically verify the aetiology of metabolically active bone
\end{abstract}

\author{
B. Klaeser $\cdot$ J. Wiskirchen $(\bowtie) \cdot J$. Wartenberg $\cdot$ T. Weitzel $\cdot$ \\ T. Krause \\ Department of Nuclear Medicine, Inselspital, \\ Bern University Hospital and University of Bern, \\ Bern, Switzerland \\ e-mail: jakub.wiskirchen@web.de \\ J. Wiskirchen \\ Department of Radiology, Neuroradiology, and Nuclear Medicine, \\ University Hospital Tübingen, \\ Tübingen, Germany \\ R. A. Schmid \\ Department of Thoracic Surgery, Inselspital, \\ Bern University Hospital and University of Bern, \\ Bern, Switzerland \\ M. D. Mueller \\ Department of Obstetrics and Gynaecology, Inselspital, \\ Bern University Hospital and University of Bern, \\ Bern, Switzerland
}

lesions without a morphological correlate confirming the suspicion of metastases in 15 patients, to determine the origin of suspected metastases in 3 patients and to evaluate the appropriateness of targeted therapy options in 2 patients. Biopsies were technically successful in all patients. In 19 of 20 patients a definite histological diagnosis was possible. No complications or adverse effects occurred. The result of PET/CT-guided bone biopsies determined a change of the planned treatment in overall $56 \%$ of patients, with intramodality changes, e.g. chemotherapy with palliative instead of curative intent, and intermodality changes, e.g. systemic therapy instead of surgery, in 22 and $50 \%$, respectively.

Conclusion PET/CT-guided bone biopsies are a promising alternative to conventional techniques to make metabolically active bone lesions - especially without a distinctive morphological correlate - accessible for histological verification. PET/CT-guided biopsies had a major clinical impact in patients who otherwise cannot be reliably stage grouped at the time of treatment decisions.

Keywords Image-guided bone biopsy PET/CT-guided biopsy - Positron emission tomography - Breast cancer . Clinical impact

\section{Introduction}

The accurate definition of tumour stages is a prerequisite for an individualized, risk-adapted therapy of cancer patients. In this context, the recognition and verification of distant metastatic disease is of utmost importance, as patients with distant metastases usually have incurable disease. Local and systemic therapy of patients in a palliative situation tends to be less aggressive and associ- 
ated with fewer side effects than therapies used with curative intent. Therefore, optimal staging may prevent patients with distant metastatic disease from receiving futile but burdensome therapies at the expense of quality of life.

$\mathrm{PET} / \mathrm{CT}$ with ${ }^{18} \mathrm{~F}$-fluorodeoxyglucose (FDG) offers excellent diagnostic accuracy for staging and restaging of a wide range of malignant tumours, among these nonsmall cell lung cancer (NSCLC), lymphoma, breast cancer and melanoma. The additional information provided by PET/CT compared with conventional staging has a major impact on treatment decisions in up to one third of patients [1-8]. However, the accumulation of FDG is not tumour specific, but FDG uptake can also occur in a number of benign conditions. Benign tumours, post-traumatic situations and inflammatory changes may mimic metastatic disease. False-positive reporting of such findings may lead to an overstaging and undertreatment of patients. On the other hand false-negative reporting may lead to a futile curative approach at the cost of quality of life in patients effectively in a palliative situation. To provide an objective fundament for treatment decisions, histological verification of lesions depicted by PET may be regarded as mandatory, for example in cases of singular occurrence of potentially stage determining findings and/or when confirmative morphological changes do not support the presumed diagnosis.

Percutaneous biopsies with image guidance by CT are well established and effectively used in routine clinical practice as minimally invasive alternatives to open surgical biopsies, with success rates reported for biopsies of morphologically clearly circumscribed lesions between 70 and $90 \%$ [9, 10]. However, metabolically active lesions without a distinctive morphological correlate are not or not reliably accessible to CT-guided biopsy and the rate of false-negative biopsies of such lesions may be substantially higher. To overcome these limitations we developed an approach for multimodal image-guided interventions using the metabolic and topographic information of PET together with CT navigation [11]. We report on our experience in patients who underwent PET/CT-guided bone biopsies for metabolically active lesions and discuss the clinical impact and applications of the method based on a survey of referring physicians.

\section{Materials and methods}

Patients

A total of 20 consecutive patients ( 15 female and 5 male) assigned to the Department of Nuclear Medicine for FDG $\mathrm{PET} / \mathrm{CT}$ in the course of primary staging $(n=10)$ or restaging $(n=10)$ of malignancies underwent PET/CT- guided bone biopsies of metabolically active lesions suspicious for metastatic disease. Patients suffered from breast cancer $(n=9)$, NSCLC $(n=5)$, melanoma $(n=2)$, uterine leiomyosarcoma $(n=1)$ (Fig. 1), ovarian cancer $(n=1)$ or lymphoma $(n=1)$. One patient had a history of more than one primary tumour, i.e. melanoma and uterine leiomyosarcoma (Table 1). The median age of the patients was 58 years (mean: 56 years, range: $41-72$ years). All patients gave written consent before the intervention and patient data were retrospectively reviewed in accordance with the regulations of the local Ethics Committee.

\section{FDG PET/CT}

PET/CT acquisitions were performed with an integrated PET/CT system (Biograph 16 HI-REZ, Siemens Medical Solutions). All patients fasted for at least $6 \mathrm{~h}$ and blood glucose level was below $10 \mathrm{mmol} / 1$ before intravenous injection of 5-7 MBq FDG/kg body weight. Emission images were obtained $90 \mathrm{~min}$ after injection $(3 \mathrm{~min}$ per bed position, scan length $16.2 \mathrm{~cm}$ per bed position) from the neck to the pelvis (5-7 bed positions) and were coregistered with an unenhanced $\mathrm{CT}$ of the same region $(120 \mathrm{kV}, 80 \mathrm{mAs}$, reconstructed slice thickness $2 \mathrm{~mm})$. Images were evaluated qualitatively in a routine clinical setting. No definite SUV cut-off values for the distinction of benign from malignant lesions were applied. Lesions were evaluated with respect to the metabolic properties of the primary tumour and/or the expected FDG uptake according to the tumour type. Patients with focal bone FDG uptake without morphological correlate or without confirmative structural changes on $\mathrm{CT}$ were considered candidates for PET/CT-guided biopsy when other PET/CT findings did not support the suspicion of distant metastases, and when no benign reason of metabolic changes was evident.

\section{PET/CT-guided bone biopsy}

PET/CT-guided bone biopsies were performed in a step-bystep technique according to a protocol previously published [11]. Interventions were either performed on the day of $\mathrm{PET} / \mathrm{CT}$ subsequently to the diagnostic examination or were scheduled on a separate day. If done on the same day, a single-bed PET/CT acquisition of the region concerned was repeated 120-180 min after injection of the radiopharmaceutical. No additional activity was given, but the acquisition time was prolonged to $5 \mathrm{~min}$ per bed position to assure adequate image quality. For interventions on a separate day a reduced dose of 3-5 MBq FDG/kg body weight was injected and the acquisition time for a singlebed PET/CT was prolonged to $5 \mathrm{~min}$ per bed position 90 min after injection. 

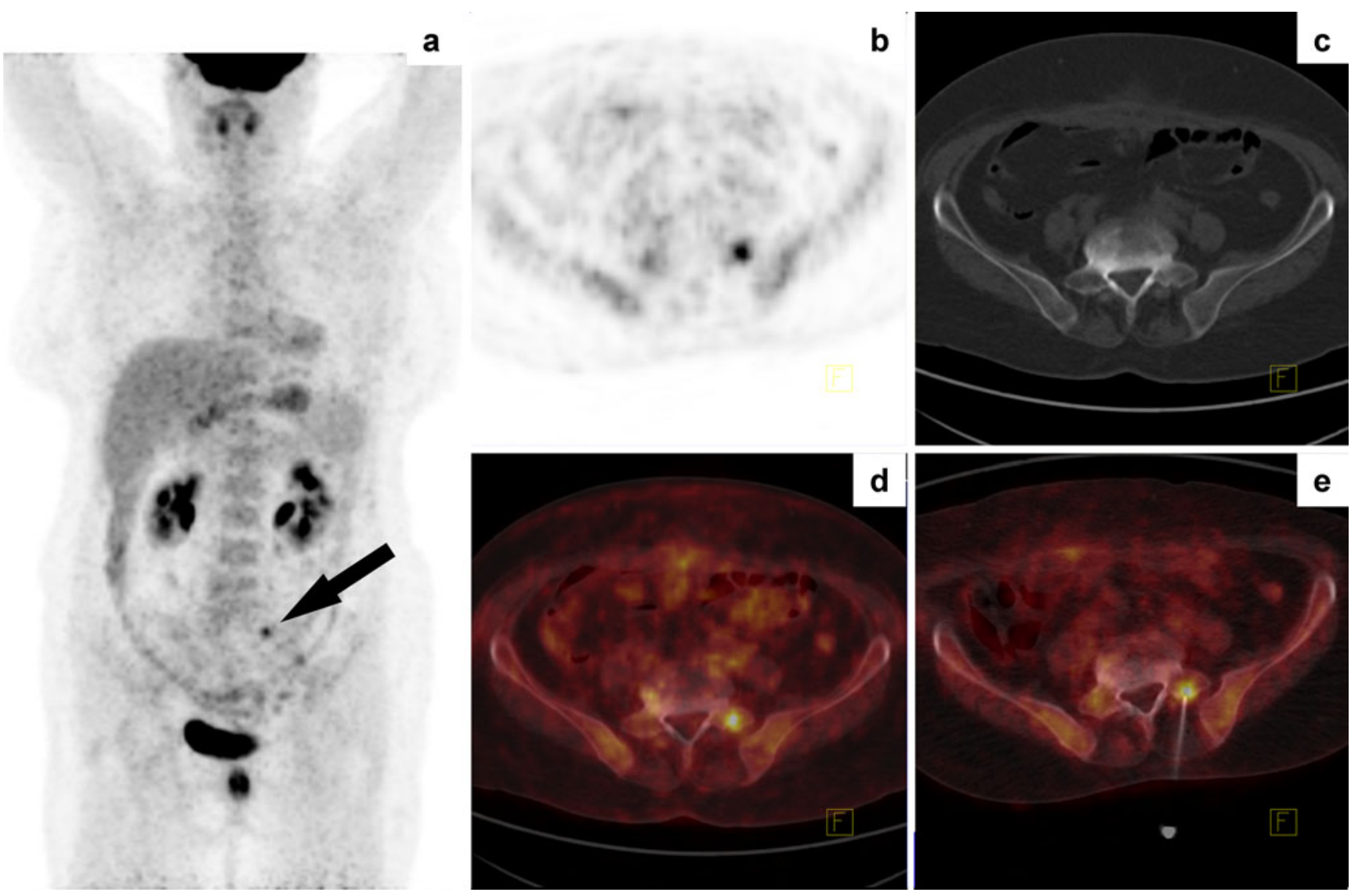

Fig. 1 A 58-year-old women with newly diagnosed uterine leiomyosarcoma. FDG PET/CT detected a solitary lesion with focally increased uptake in the left sacrum. Histological examination confirmed a bone metastasis of the uterine leiomyosarcoma

Patients were positioned in a prone or supine position depending on the localization of the lesion concerned, a single bed PET/CT acquisition of the region of interest was obtained and the access path was defined based on the PET/CT presentation of the metabolically active lesion of interest. Interventions were performed under aseptic conditions, local anaesthesia and sedation with midazolam, if necessary. The needle was introduced stepwise under CT guidance. If reasonable, the correct needle position in the centre of the hypermetabolic lesion was assured by a repeated single-bed PET/CT acquisition with the biopsy kit in place before sampling, and the biopsy needle was repositioned, if necessary. Depending on the localization and depth of the lesion either a 15G (Bonopty, AprioMed, Uppsala, Sweden) or a 10G (Promedics, Biel, Switzerland) bone biopsy kit was chosen. One or more samples were obtained in each patient, and histopathology and immunohistochemistry of each specimen was performed.

\section{Questionnaires}

Questionnaires were sent to the attending physicians to determine the clinical impact of PET/CT-guided biopsies on the planned treatment strategy. Planned treatment based on information available after FDG PET/CT (surgery, radiotherapy, chemotherapy and other treatment options such as endocrine therapy or bisphosphonates) and changes of the treatment plan after PET/CT-guided bone biopsies were recorded. The relevance of additional information gained by biopsies for confidence in diagnoses and treatment decisions as well as for patient communication was defined. In addition, we requested a general assessment of PET/CTguided interventions as a recently established part of the department's range of services and of its influence on clinical practice.

\section{Results}

Clinical indication for tissue sampling

Biopsies were indicated in 15 patients to clarify the aetiology of unexpected focal bone FDG uptake that did not demonstrate confirmative morphological changes and/ or was the sole sign of distant metastases. In two of these patients a benign diagnosis was favoured before biopsy 
Table 1 Patient characteristics and punctures

\begin{tabular}{|c|c|c|c|c|c|c|c|c|}
\hline & \multirow[t]{2}{*}{ Diagnosis } & \multirow{2}{*}{$\begin{array}{l}\text { Indication for } \\
\mathrm{PET} / \mathrm{CT}\end{array}$} & \multirow{2}{*}{$\begin{array}{l}\text { Localization of } \\
\text { biopsy }\end{array}$} & \multicolumn{2}{|l|}{ Lesion } & \multirow[t]{2}{*}{ Histology } & \multicolumn{2}{|l|}{ Success } \\
\hline & & & & Diameter & Depth & & Technical & Clinical \\
\hline 1 & Breast cancer & Primary staging & L5 & $8 \mathrm{~mm}$ & $11 \mathrm{~cm}$ & Breast cancer & Yes & Yes \\
\hline 2 & Breast cancer & Recurrence & Scapula & $8 \mathrm{~mm}$ & $3 \mathrm{~cm}$ & Breast cancer & Yes & Yes \\
\hline 3 & Breast cancer & Recurrence & Acetabulum & $12 \mathrm{~mm}^{\mathrm{a}}$ & $10 \mathrm{~cm}$ & Breast cancer & Yes & Yes \\
\hline 4 & NSCLC, DD sarcoidosis & Primary staging & $\mathrm{T} 8$ & $10 \mathrm{~mm}$ & $7 \mathrm{~cm}$ & NSCLC & Yes & Yes \\
\hline 5 & Breast cancer, DD NSCLC & Recurrence & T6 & $24 \mathrm{~mm}^{\mathrm{a}}$ & $8 \mathrm{~cm}$ & Adenocarcinoma $^{\mathrm{b}}$ & Yes & $\mathrm{No}^{\mathrm{b}}$ \\
\hline 6 & NSCLC & Primary staging & Sacroiliac joint & $10 \mathrm{~mm}$ & $6 \mathrm{~cm}$ & Inflammation & Yes & Yes \\
\hline 7 & $\begin{array}{l}\text { Melanoma, uterine } \\
\text { leiomyosarcoma }\end{array}$ & Recurrence & Trochanter & $24 \mathrm{~mm}^{\mathrm{a}}$ & $5 \mathrm{~cm}$ & $\begin{array}{l}\text { Uterine } \\
\text { leiomyosarcoma }\end{array}$ & Yes & Yes \\
\hline 8 & Uterine leiomyosarcoma & Primary staging & $\mathrm{S} 1$ & $8 \mathrm{~mm}^{\mathrm{a}}$ & $7 \mathrm{~cm}$ & $\begin{array}{l}\text { Uterine } \\
\text { leiomyosarcoma }\end{array}$ & Yes & Yes \\
\hline 9 & Melanoma & Recurrence & Os ilium & $30 \mathrm{~mm}$ & $4 \mathrm{~cm}$ & Melanoma & Yes & Yes \\
\hline 10 & NSCLC & $\begin{array}{l}\text { During } \\
\text { chemotherapy }\end{array}$ & 5th rib & $12 \mathrm{~mm}^{\mathrm{a}}$ & $3 \mathrm{~cm}$ & NSCLC & Yes & Yes \\
\hline 11 & Ovarian cancer & Recurrence & L3 & $30 \mathrm{~mm}$ & $9 \mathrm{~cm}$ & Ovarian cancer & Yes & Yes \\
\hline 12 & Melanoma & Follow-up & Os ischium & $10 \mathrm{~mm}$ & $11 \mathrm{~cm}$ & Prostate cancer & Yes & Yes \\
\hline 13 & NSCLC & Primary staging & Os ilium & $28 \mathrm{~mm}$ & $9 \mathrm{~cm}$ & NSCLC & Yes & Yes \\
\hline 14 & Breast cancer & Primary staging & $\mathrm{T} 12$ & $17 \mathrm{~mm}$ & $9 \mathrm{~cm}$ & Breast cancer & Yes & Yes \\
\hline 15 & Hodgkin's lymphoma & Primary staging & $\mathrm{S} 2 / \mathrm{S} 3$ & $18 \mathrm{~mm}^{\mathrm{a}}$ & $6 \mathrm{~cm}$ & $\begin{array}{l}\text { Hodgkin's } \\
\text { lymphoma }\end{array}$ & Yes & Yes \\
\hline 16 & Breast cancer & Recurrence & Sacrum & $20 \mathrm{~mm}^{\mathrm{a}}$ & $6 \mathrm{~cm}$ & Breast cancer & Yes & Yes \\
\hline 17 & NSCLC & Primary staging & $\mathrm{L} 1$ & $28 \mathrm{~mm}$ & $4 \mathrm{~cm}$ & NSCLC & Yes & Yes \\
\hline 18 & Breast cancer & Primary staging & Symphysis & $17 \mathrm{~mm}$ & $2 \mathrm{~cm}$ & Breast cancer & Yes & Yes \\
\hline 19 & $\begin{array}{l}\text { Breast cancer, DD } \\
\text { spondylodiscitis }\end{array}$ & Recurrence & S1 & $28 \mathrm{~mm}^{\mathrm{a}}$ & $7 \mathrm{~cm}$ & Breast cancer & Yes & Yes \\
\hline 20 & Breast cancer & Recurrence & 8th rib & $10 \mathrm{~mm}$ & $3 \mathrm{~cm}$ & Breast cancer & Yes & Yes \\
\hline
\end{tabular}

${ }^{\mathrm{a}}$ Not delineable based on CT information; diameter estimated based on the PET appearance alone (diameter at a threshold value of $70 \%$ of $S U V_{\text {max }}$ )

${ }^{\mathrm{b}}$ Determination of the primary tumour not possible due to negative immunohistochemistry

based on imaging findings and clinical history, i.e. sarcoidosis and spondylodiscitis, and biopsy was performed to rule out malignancy before onset of therapy.

PET/CT-guided biopsy was indicated to histologically determine the origin of bone metastases in one patient with a history of two primary tumours and in two patients when PET/CT raised the suspicion of a second primary tumour.

In two patients tissue sampling and characterization were requested to evaluate the appropriateness of targeted therapy options.

\section{PET/CT-guided bone biopsy}

The hypermetabolic bone lesions of interest were successfully targeted and representative tissue samples of the metabolically active sites could be obtained in all patients $(n=20)$. Bone metastases were confirmed in 14 of 15 patients who presented with FDG-avid lesions that appeared morphologically unremarkable or ambiguous on CT. Both patients with a benign diagnosis previously postulated based on imaging findings had bone metastases.
One of these patients with a spondylodiscitis previously suspected on magnetic resonance imaging (MRI) received systemic therapy after verification of a tumour recurrence. In the other patient with NSCLC, findings on PET/CT were regarded compatible with a pulmonary and bone sarcoidosis, but biopsy confirmed the palliative situation with bone metastases. In one patient with newly diagnosed NSCLC, a suspected bone metastasis in the ilium was confirmed to represent an inflammatory process, and treatment with curative intent was initiated.

The origin of metastases could be determined in two of three patients with more than one primary tumour known or suspected before biopsy. In the third patient the histological examination revealed a metastasis, but the origin could not be determined by the immunohistochemistry profile.

Representative tissue samples for characterization of metastases could be provided in two patients biopsied to evaluate the appropriateness of targeted therapy options, e.g. hormone receptor and HER2/neu status of the metastasis before onset of a treatment with an aromatase inhibitor and/or trastuzumab. 
Of all 20 biopsies performed because of the unclear nature of FDG-avid bone lesions $(n=15)$, to determine the origin of metastases in patients with more than one (suspected) primary tumour $(n=3)$, or to evaluate for the appropriateness of targeted therapies $(n=2)$, bone lesions did not show a morphological CT correlate in 8 patients, and in 11 patients the lesions punctured presented an indeterminate and/or unreliably delineable morphological appearance on CT. The size of metabolically active lesions without a distinctive morphological correlate was measured on CT, as far as lesions were morphologically traceable aware of the PET information $(n=11)$. The diameter of lesions without any CT correlate was estimated based on the PET appearance alone (diameter of the FDG-avid lesion measured at a threshold value of $70 \%$ of $\mathrm{SUV}_{\max }, n=8$ ). The median diameter of all lesions punctured was $17 \mathrm{~mm}$ (mean: $18 \mathrm{~mm}$, range: $8-30 \mathrm{~mm}$ ). One patient had a sclerotic lesion clearly delineable on CT (diameter $10 \mathrm{~mm}$, Fig. 2). The median length of the access path was $6.3 \mathrm{~cm}$ (mean: $6.5 \mathrm{~cm}$, range: $2-11 \mathrm{~cm}$ ). Lesions were located in the spine in six, in the pelvic bones in ten, in a rib in two and in the scapula and femur in one patient, respectively (Table 1). Total intervention time varied between 40 and
$70 \mathrm{~min}$, depending on the localization of biopsies and the necessity of repeated PET/CT acquisitions to assure correct sampling of the metabolically active lesion.

Side effects and complications

Of 20 patients, 17 were treated on an outpatient basis and could be released on average $1 \mathrm{~h}$ after completion of the intervention; 3 were scheduled for biopsy during hospitalization. Interventions were well tolerated under local anaesthesia. Three patients with claustrophobia had midazolam 2-5 $\mathrm{mg}$ for short-term sedation. No near-term adverse effects (e.g. major bleeding, pneumothorax, infection) occurred in any patient, and all patients were released in good physical status. No complications during follow-up were reported in the questionnaires.

\section{Clinical value of PET/CT-guided biopsies}

Questionnaires were completed and returned by 13 of 15 of the attending physicians for 18 of 20 patients (response rate 90\%). Changes of the original treatment plan after PET/CTguided biopsies are listed in Table 2. Based on the available
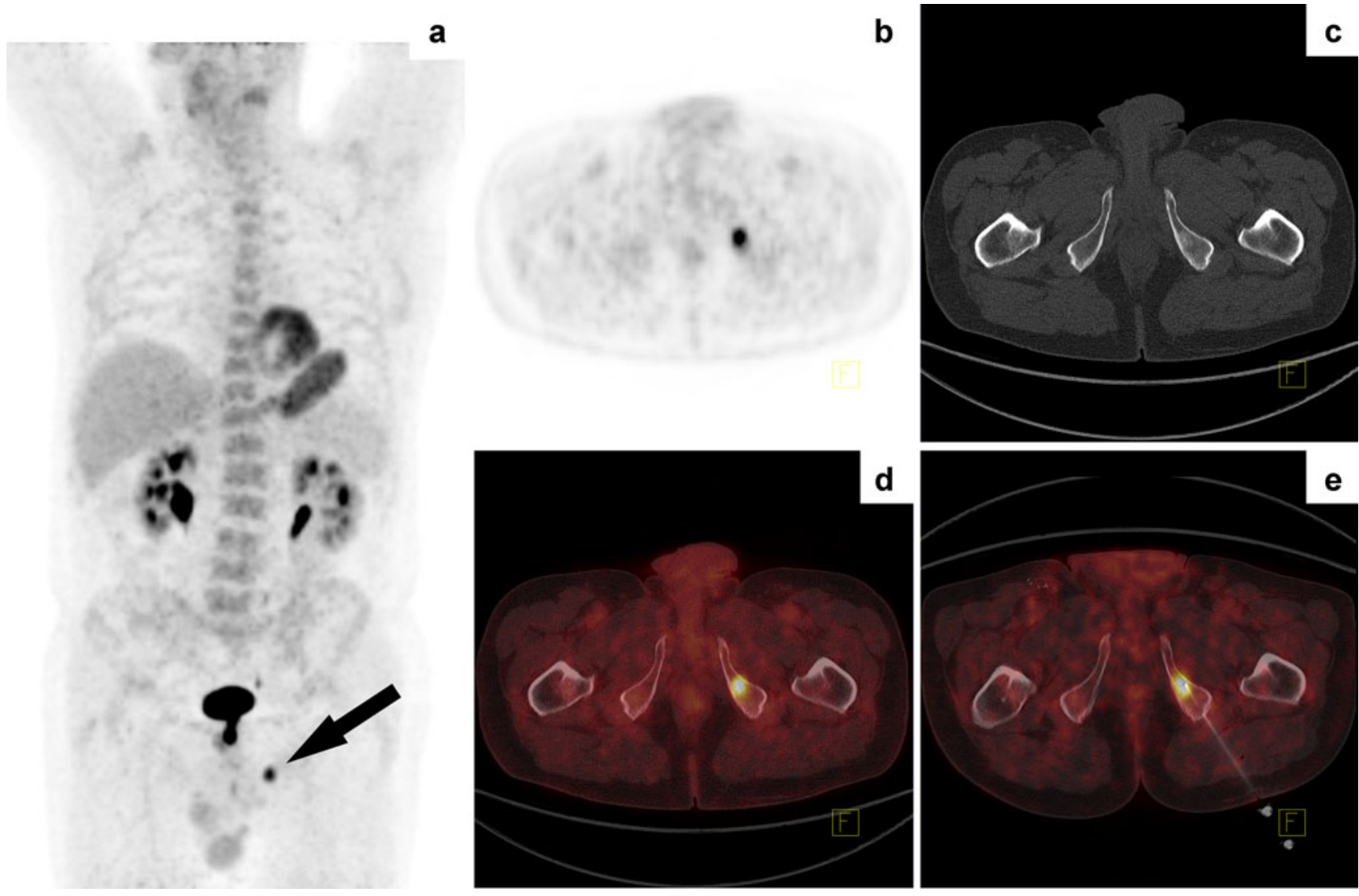

Fig. 2 Follow-up examination of a 67-year-old patient with a history of malignant melanoma. FDG PET/CT showed an unexpected FDGavid lesion in the periphery of the prostate and a singular FDG-avid sclerotic lesion in the left ischium. Bone biopsy revealed a metastasis of prostate cancer and confirmed the presence of a second primary tumour 
Table 2 Planned treatment and changes of treatment plan after $\mathrm{PET} / \mathrm{CT}$ and PET/CT-guided biopsies

\begin{tabular}{|c|c|c|c|c|}
\hline & \multicolumn{4}{|c|}{ Planned treatment after } \\
\hline & \multicolumn{2}{|c|}{$\mathrm{PET} / \mathrm{CT}$} & \multicolumn{2}{|c|}{ PET/CT-guided biopsy } \\
\hline & $n$ & $\%$ & $n$ & $\%$ \\
\hline Not defined & $8 / 18$ & 44 & $1 / 18$ & 6 \\
\hline Surgery & $3 / 18$ & 17 & $4 / 18$ & 22 \\
\hline Radiotherapy & $2 / 18$ & 11 & $3 / 18$ & 17 \\
\hline \multicolumn{5}{|l|}{ Chemotherapy } \\
\hline Curative intent & $1 / 18$ & 6 & $1 / 18$ & 6 \\
\hline Palliative intent & $3 / 18$ & 17 & $11 / 18$ & 61 \\
\hline \multirow[t]{3}{*}{ Other $^{\mathrm{a}}$} & $2 / 18$ & 11 & $4 / 18$ & 22 \\
\hline & & & \multicolumn{2}{|c|}{ Changes of treatment plan after } \\
\hline & & & \multicolumn{2}{|c|}{ PET/CT-guided biopsy } \\
\hline All & & & $10 / 18$ & 56 \\
\hline Intramodality & & & $4 / 18$ & 22 \\
\hline Intermodality & & & $9 / 18$ & 50 \\
\hline
\end{tabular}

${ }^{a}$ i.e. endocrine therapy, bisphosphonates

information a treatment decision was not possible, and further investigations were regarded as necessary in $44 \%$ of patients after PET/CT and in 1 of 20 patients $(6 \%$, primary tumour unclear according to histopathology and immunohistochemistry) after PET/CT-guided biopsy. Overall, the treatment plan was modified after biopsy in $56 \%$ of patients, with intramodality changes, e.g. chemotherapy with palliative instead of curative intent, and intermodality changes, e.g. systemic therapy instead of surgery, in 22 and $50 \%$, respectively. In eight patients the histological result of biopsies did not modify planned treatment, but the confidence in treatment decisions was increased in all cases. The relevance of information gained by biopsies to communicate treatment options with the patient was categorized as high or very high in $83 \%$, moderate in $11 \%$ and low in $6 \%$.

All referring physicians interviewed judged PET/CTguided biopsies as a reasonable complement to the diagnostic spectrum of our department. Of those, $61 \%$ generally appreciated the possibility of a one-stop shop comprising PET/CT and histological verification of suspicious findings, and $41 \%$ valued PET/CT-guided biopsies in selected cases, i.e. when lesions cannot be reliably targeted by other means.

\section{Discussion}

PET/CT has evolved as the standard of care imaging modality in the diagnostic work-up of many tumours
$[12,13]$ and clarifies true stage grouping in up to one third of patients compared with conventional staging $[2,6,8,14$, 15]. Despite the excellent diagnostic accuracy of PET/CT, it remains impossible in a number of patients with focal tracer uptake in the skeleton to reliably determine the tumour stage based on the imaging information alone. A number of benign bone tumours such as fibrous dysplasia [16-19], Paget disease [20], sarcoidosis [21], giant cell tumours and Langerhans cell histiocytosis [16] have been described to show FDG uptake comparable to malignant bone tumours and eventually can mimic bone metastases $[16,22]$. The same is true for inflammatory and infectious changes, e.g. Brodie abscesses, atypical appearances of osteoarthritis and post-traumatic changes that can also show a variable degree of FDG uptake and occasionally can be difficult to separate from metastases [22, 23]. It is evident that the aetiology of such indeterminate findings on PET/CT must be evaluated prudently before a treatment decision with curative or palliative intent is reached, to avoid under- and overtreatment, and consequently to maintain optimal management and quality of life in cancer patients. This is especially true for solitary suspected distant metastases and for metabolically active lesions without confirmative structural changes on the coregistered CT. MRI provides higher sensitivity than CT and a diagnostic performance comparable to PET/CT in the detection of bone metastases and may be considered to further evaluate suspicious findings [24, 25]. However, when small, singular and/or ambiguous lesions with a low or moderate pre-test probability have to be evaluated, even imaging tests with an overall excellent accuracy such as PET/CT and MRI may not be regarded as accurate enough in an individual patient, and it comes to be a question of "knowing" instead of "guessing" when a decision for a therapeutic concept with palliative vs curative intent has to be made. In such cases it is mandatory that suspicious findings are confirmed histologically.

Image-guided punctures are well established as a minimally invasive technique to provide tissue samples for histological work-up of bone lesions. CT-guided biopsies, for example, allow for successful sampling in $70-90 \%$ of cases with morphologically clearly circumscribed lesions $[9,10]$, but the success rate of biopsies may be substantially lower for lesions that are characterized by their metabolic properties rather than by structural changes. Under such circumstances non-representative tissue sampling and false-negative biopsies may occur, especially when PET imaging and interventions are performed by different persons, at different time points, using different devices or when positioning the patient differently. Another issue in a routine setting may be the reservation of the interventionist to accept such patients for biopsy, as it is difficult from the radiologist's perspective to justify risk 
and complications associated with an intervention in cases of a lesion with indeterminate or even benign morphological appearance.

$\mathrm{PET} / \mathrm{CT}$ guidance offers the opportunity to directly puncture the metabolically active lesion irrespective of structural landmarks, to reliably obtain representative tissue samples and therefore to avoid futile biopsy attempts. In situations as illustrated in Figs. 1 and 3, i.e. bone FDG uptake in morphologically unremarkable or indeterminate lesions, and without a typical pattern of other lesions supporting the suspicion of metastases, PET/CT-guided biopsies allow for a definite diagnosis. Histopathological verification of suspected metastases may also be necessary when patients suffer from more than one primary tumour or when a second primary is suspected based on PET/CT. Incidental PET findings suggesting a previously unknown second malignancy were reported to occur in 3-6\% of all patients, and a second primary tumour may be proven in about one third of those cases [26-28]. An example is provided in Fig. 2 where the indication for biopsy was to determine the source of a probable bone metastasis, as the therapeutic concept would be completely different depend- ing on the histological result. With the increasing availability of individualized tumour-specific therapies, we expect accordingly a rising demand for the characterization of metastases before selection of the appropriate therapeutic agents (Fig. 4). Besides such clinical applications, PET/CTguided interventions may serve as an optimal reference standard in the context of diagnostic studies, as this technique minimizes the risk of sampling errors compared to morphology-guided biopsy techniques.

According to our experience, even small lesions without a CT correlate can be punctured reliably, as the correct needle positioning can be ascertained by a repeated regional PET/CT before tissue sampling. A negative histological result may be regarded as true-negative and a sampling error can be excluded when the specimen was obtained after verified needle positioning in the centre of the metabolically active lesion. In the group of patients reported, all bone biopsies could be accomplished successfully, i.e. the biopsy needle was positioned correctly in the lesion of interest, and a clinically useful histological result could be obtained in $95 \%$ of patients. The high rate of metastases was surprising given that many lesions biopsied
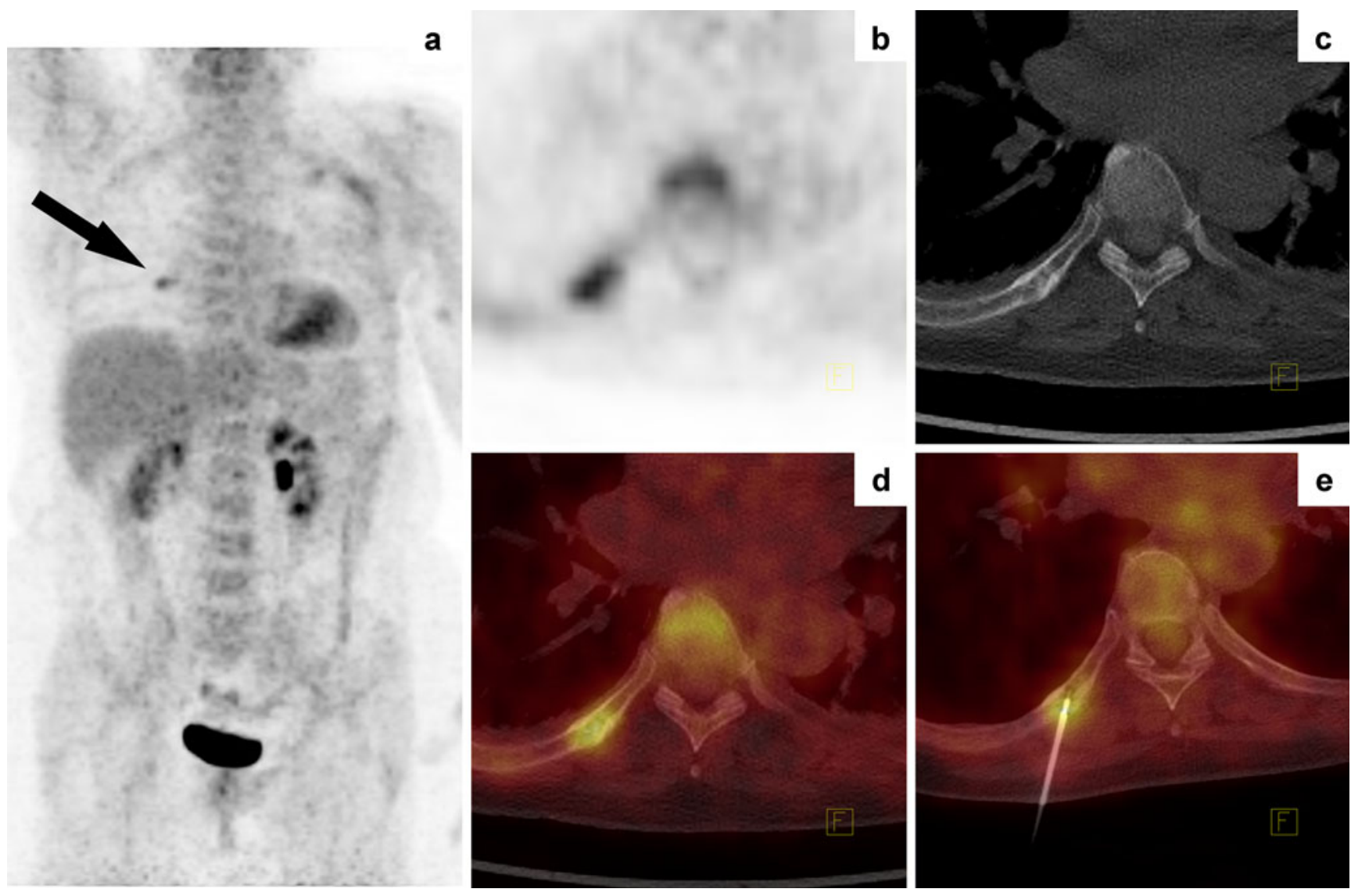

Fig. 3 A 61-year-old patient with operated breast cancer. PET/CT staging showed a moderately FDG-avid lesion in the 8th rib on the right with an indeterminate morphological appearance. PET/CT-guided biopsy revealed a solitary bone metastasis 


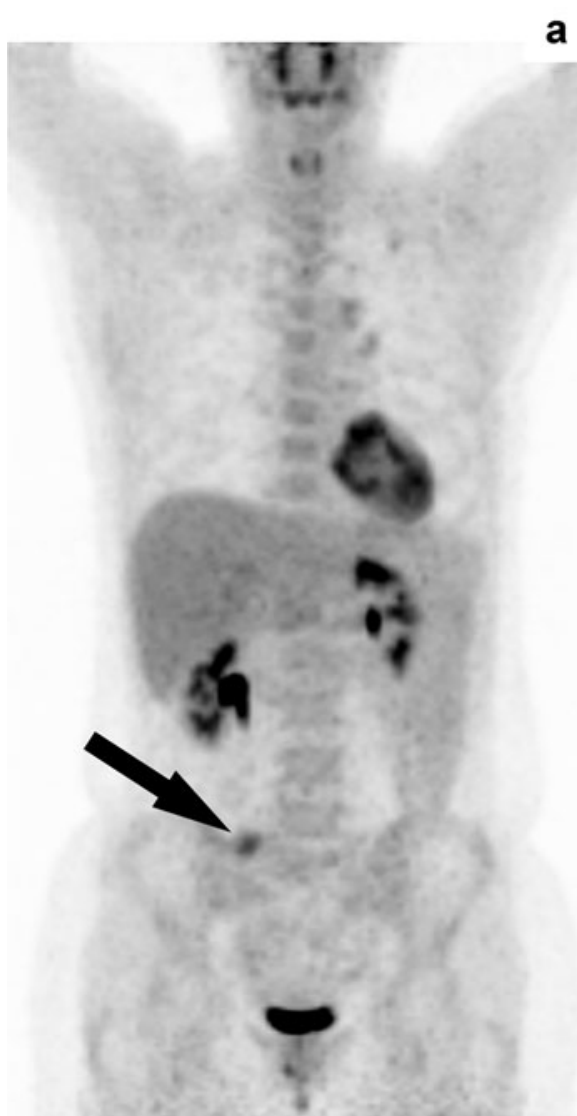

a
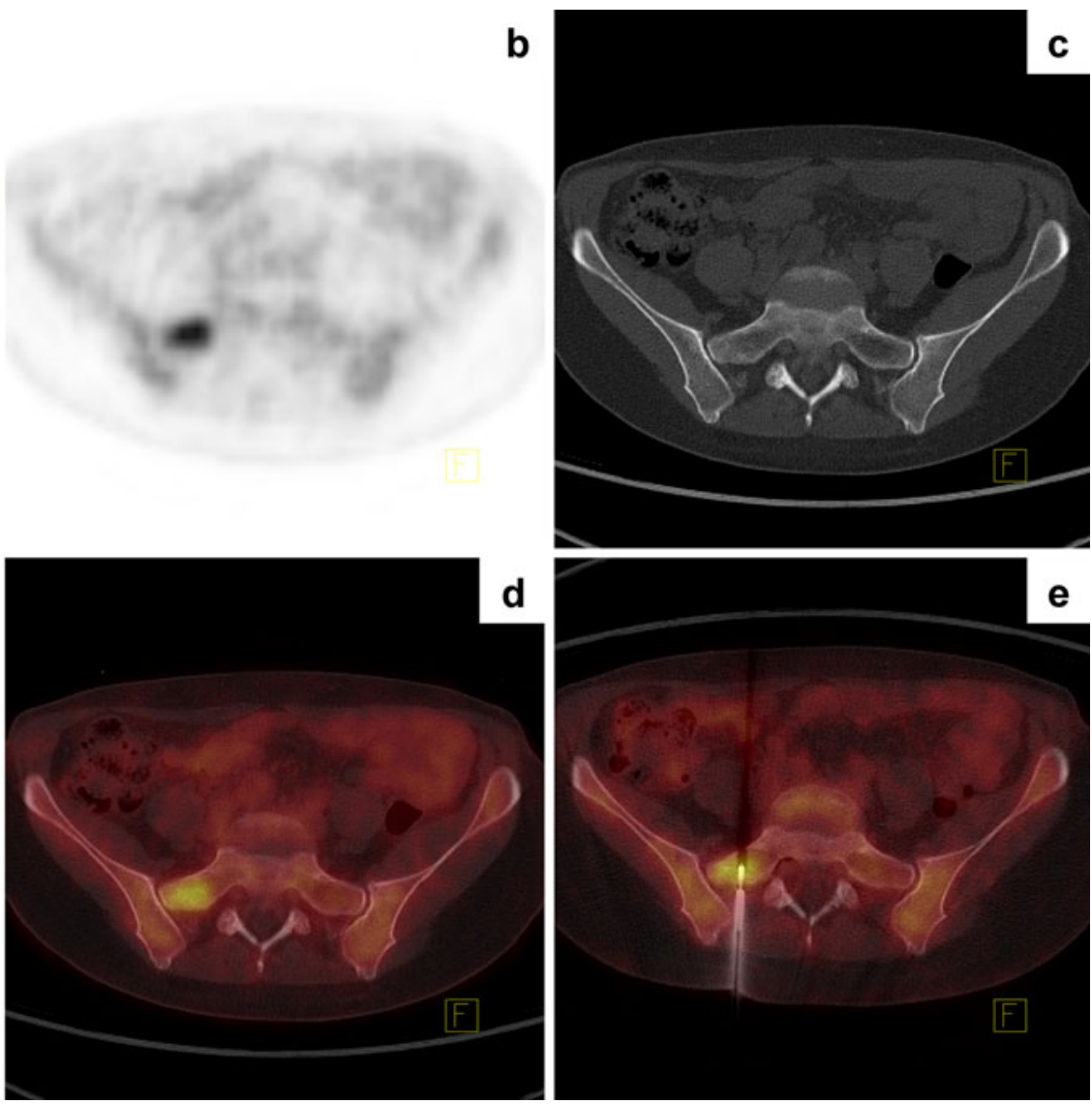

Fig. 4 Restaging of a 48-year-old patient with breast cancer. PET/CT revealed a lymphatic recurrence and a bone metastasis without morphological correlate in the sacrum. Oestrogen, progesterone and

were considered of intermediate risk to represent malignancy based on the PET/CT appearance, and a lower rate of malignant findings might be expected in a larger series.

Overall, patient management was modified according to the results of PET/CT-guided biopsies in $56 \%$ of cases. The original treatment plan was altered in terms of intramodality changes in $22 \%$ of patients, and the composition of intended treatment modalities was changed in $50 \%$ of patients. In most cases, intermodality changes were due to the diagnosis of distant metastatic spread, i.e. the therapeutic concept was shifted from a curative to a palliative approach. In this context, the availability of a histologically verified stage grouping was considered relevant or very relevant for patient communication in $83 \%$ of cases, and the immediate verification of distant metastases prevented futile therapies with curative intent in more than half of all patients. In general, PET/CT-guided interventions were regarded as a reasonable extension of the diagnostic spectrum of our PET unit, either as an alternative approach to assess morphologically unremarkable PET findings, and/ or as a diagnostic one-stop shop staging with histological verification of suspected distant metastases.
HER2/neu status of the metastasis was determined by PET/CT-guided biopsy before therapy decision

PET/CT-guided biopsies were performed in a manner similar to routine CT-guided punctures, i.e. the lesion of interest was targeted in a step-by-step technique with repeated CT control scans to verify the needle position. Although clinically absolutely reliable, the time needed for PET/CT-guided interventions in this technique has a number of drawbacks, e.g. the costs related to the occupancy of the PET/CT machine, the discomfort for the patient and the radiation burden for the interventionist originating from the patient. We are currently evaluating a dedicated system for computer-aided navigation based on $\mathrm{PET} / \mathrm{CT}$ to reduce intervention time and to optimize the conditions for the routine clinical use of PET/CT-guided interventions.

\section{Conclusion}

PET/CT guidance offers the opportunity to precisely target even small and morphologically indeterminate bone lesions for tissue sampling. In a routine setting PET/CTguided biopsies had a major clinical impact in patients 
with singular suspected bone metastases, when the morphological appearance of hypermetabolic lesions did not support the suspicion of metastases, and to evaluate the appropriateness of targeted therapy regimens. Besides this, PET/CT-guided biopsies may serve as a minimally invasive alternative for representative sampling of metabolically active tissue in the context of diagnostic and clinical studies.

Acknowledgements B.K., J.W. and T.K. were supported by a local quality assurance project.

Conflicts of interest None.

\section{References}

1. Subedi N, Scarsbrook A, Darby M, Korde K, Mc Shane P, Muers MF. The clinical impact of integrated FDG PET-CT on management decisions in patients with lung cancer. Lung Cancer 2009;64:301-7. doi:10.1016/j.lungcan.2008.09.006.

2. Lardinois D, Weder W, Hany TF, Kamel EM, Korom S, Seifert $\mathrm{B}$, et al. Staging of non-small-cell lung cancer with integrated positron-emission tomography and computed tomography. N Engl J Med 2003;348:2500-7. doi:10.1056/NEJMoa022136 348/25/2500

3. Naumann R, Beuthien-Baumann B, Reiss A, Schulze J, Hänel A, Bredow J, et al. Substantial impact of FDG PET imaging on the therapy decision in patients with early-stage Hodgkin's lymphoma. Br J Cancer 2004;90:620-5. doi:10.1038/sj.bjc.6601561 6601561.

4. Allen-Auerbach M, de Vos S, Czernin J. The impact of fluorodeoxyglucose-positron emission tomography in primary staging and patient management in lymphoma patients. Radiol Clin North Am 2008;46:199-211. doi:10.1016/j.rcl.2008.03.004. vii.

5. Groheux D, Moretti JL, Baillet G, Espie M, Giacchetti S, Hindie E, et al. Effect of (18)F-FDG PET/CT imaging in patients with clinical stage II and III breast cancer. Int J Radiat Oncol Biol Phys 2008;71:695-704. doi:10.1016/j.ijrobp.2008.02.056.

6. Klaeser B, Wiederkehr O, Koeberle D, Mueller A, Bubeck B, Thuerlimann B. Therapeutic impact of 2-[fluorine-18]fluoro-2deoxy-D-glucose positron emission tomography in the pre- and postoperative staging of patients with clinically intermediate or high-risk breast cancer. Ann Oncol 2007;18:1329-34. doi:10.1093/annonc/mdm139.

7. Borrego Dorado I, Vázquez Albertino R, López Martín J, Alvarez Pérez RM. Evaluation of efficacy and clinical impact of FDG-PET on patients with suspicion of recurrent cutaneous melanoma. Rev Esp Med Nucl 2006;25:301-11. 13092697.

8. Bastiaannet E, Wobbes T, Hoekstra OS, van der Jagt EJ, Brouwers $\mathrm{AH}$, Koelemij R, et al. Prospective comparison of [18F]fluorodeoxyglucose positron emission tomography and computed tomography in patients with melanoma with palpable lymph node metastases: diagnostic accuracy and impact on treatment. J Clin Oncol 2009;27:4774-80. doi:10.1200/JCO.2008.20.1822.

9. Huch K, Röderer G, Ulmar B, Reichel H. CT-guided interventions in orthopedics. Arch Orthop Trauma Surg 2007;127:677-83. doi:10.1007/s00402-007-0410-z.

10. Lis E, Bilsky MH, Pisinski L, Boland P, Healey JH, O'Malley B, et al. Percutaneous CT-guided biopsy of osseous lesion of the spine in patients with known or suspected malignancy. AJNR Am J Neuroradiol 2004;25:1583-8. 25/9/1583.
11. Klaeser B, Mueller MD, Schmid RA, Guevara C, Krause T, Wiskirchen J. PET-CT-guided interventions in the management of FDG-positive lesions in patients suffering from solid malignancies: initial experiences. Eur Radiol 2009;19:1780-5. doi:10.1007/ s00330-009-1338-1.

12. Czernin J, Allen-Auerbach $M$, Schelbert HR. Improvements in cancer staging with PET/CT: literature-based evidence as of September 2006. J Nucl Med 2007;48 Suppl 1:78S-88. 48/1_suppl/78S.

13. Poeppel TD, Krause BJ, Heusner TA, Boy C, Bockisch A, Antoch G. PET/CT for the staging and follow-up of patients with malignancies. Eur J Radiol 2009;70:382-92. doi:10.1016/j. ejrad.2009.03.051.

14. Park JY, Kim EN, Kim DY, Suh DS, Kim JH, Kim YM, et al. Role of PET or PET/CT in the post-therapy surveillance of uterine sarcoma. Gynecol Oncol 2008;109:255-62. doi:10.1016/j. ygyno.2008.01.030.

15. Kitajima K, Murakami K, Yamasaki E, Kaji Y, Fukasawa I, Inaba $\mathrm{N}$, et al. Diagnostic accuracy of integrated FDG-PET/contrastenhanced $\mathrm{CT}$ in staging ovarian cancer: comparison with enhanced CT. Eur J Nucl Med Mol Imaging 2008;35:1912-20. doi:10.1007/s00259-008-0890-2.

16. Aoki J, Watanabe H, Shinozaki T, Takagishi K, Ishijima H, Oya $\mathrm{N}$, et al. FDG PET of primary benign and malignant bone tumors: standardized uptake value in 52 lesions. Radiology 2001;219:774-7.

17. Charest M, Singnurkar A, Hickeson M, Novales JA, Derbekyan V. Intensity of FDG uptake is not everything: synchronous liposarcoma and fibrous dysplasia in the same patient on FDG PETCT imaging. Clin Nucl Med 2008;33:455-8. doi:10.1097/RLU. 0b013e31817793bb 00003072-200807000-00001.

18. Strobel K, Bode B, Lardinois D, Exner U. PET-positive fibrous dysplasia - a potentially misleading incidental finding in a patient with intimal sarcoma of the pulmonary artery. Skeletal Radiol 2007;36 Suppl 1:S24-8. doi:10.1007/s00256006-0152-y.

19. Stegger L, Juergens KU, Kliesch S, Wormanns D, Weckesser M. Unexpected finding of elevated glucose uptake in fibrous dysplasia mimicking malignancy: contradicting metabolism and morphology in combined PET/CT. Eur Radiol 2007;17:1784-6. doi:10.1007/s00330-006-0466-0.

20. Mahmood S, Martinez de Llano SR. Paget disease of the humerus mimicking metastatic disease in a patient with metastatic malignant mesothelioma on whole body F-18 FDG PET/CT. Clin Nucl Med 2008;33:510-2. doi:10.1097/RLU. 0b013e318177928a 00003072-200807000-00019.

21. Ludwig V, Fordice S, Lamar R, Martin WH, Delbeke D. Unsuspected skeletal sarcoidosis mimicking metastatic disease on FDG positron emission tomography and bone scintigraphy. Clin Nucl Med 2003;28:176-9. doi:10.1097/01. RLU.0000053528.35645.70.

22. Strobel K, Exner UE, Stumpe KD, Hany TF, Bode B, Mende K, et al. The additional value of $\mathrm{CT}$ images interpretation in the differential diagnosis of benign vs. malignant primary bone lesions with 18F-FDG-PET/CT. Eur J Nucl Med Mol Imaging 2008;35:2000-8. doi:10.1007/s00259-008-0876-0.

23. Metser U, Miller E, Lerman H, Even-Sapir E. Benign nonphysiologic lesions with increased 18F-FDG uptake on PET/CT: characterization and incidence. AJR Am J Roentgenol 2007;189:1203-10. doi:10.2214/AJR.07.2083.

24. Buhmann Kirchhoff S, Becker C, Duerr HR, Reiser M, BaurMelnyk A. Detection of osseous metastases of the spine: comparison of high resolution multi-detector-CT with MRI. Eur J Radiol 2009;69:567-73. doi:10.1016/j.ejrad.2007.11.039.

25. Heusner T, Gölitz P, Hamami M, Eberhardt W, Esser S, Forsting $\mathrm{M}$, et al. "One-stop-shop" staging: should we prefer FDG-PET/CT 
or MRI for the detection of bone metastases? Eur J Radiol 2009. doi:10.1016/j.ejrad.2009.10.031.

26. Ishimori T, Patel PV, Wahl RL. Detection of unexpected additional primary malignancies with PET/CT. J Nucl Med 2005;46:752-7. 46/5/752.

27. van Westreenen HL, Westerterp M, Jager PL, van Dullemen HM, Sloof GW, Comans EF, et al. Synchronous primary neoplasms detected on 18F-FDG PET in staging of patients with esophageal cancer. J Nucl Med 2005;46:1321-5. 46/8/ 1321.

28. Wang G, Lau EW, Shakher R, Rischin D, Ware RE, Hong E, et al. How do oncologists deal with incidental abnormalities on wholebody fluorine-18 fluorodeoxyglucose PET/CT? Cancer 2007;109:117-24. doi:10.1002/cncr.22370. 